ROLES Y ESTRATEGIAS DE LOS GOBIERNOS INDÍGENAS

\title{
en el sistema de salud colombiano
}

\author{
Claudia Puerta Silva \\ InVEStigadora asociada al InStituto de Estudios Regionales \\ (Iner) de La Universidad de Antioquia, Medellín \\ claudiapuerta@hotmail.com
}

\begin{abstract}
Resumen
B asado en los trabajos etnográficos con dos comunidades wayuU de La Guajira -un resguardo y una asociación de autoridades tradicionales-, el artículo analiza el desempeño de los gobiernos indígenas en el funcionamiento del sistema de salud: por un lado, las condiciones de su participación en el sistema -los márgenes de maniobra para desempeñar sus roles-; y, por otro, las estrategias de estos gobiernos para garantizar el desarrollo de la salud de sus poblaciones. El estudio muestra una de las características de los sistemas multicultural es: son amplios y general es en la regulación, pero poco flexibles en el nivel (local) de la implementación de las políticas. Finalmente, las estrategias de los actores reflejan el margen de maniobra que les permite el sistema para su desempeño como agentes local es; pero los resultados dependen, a su vez, de las lógicas institucional es y las dinámicas sociocultural es locales.

Palabras Clave: sistema de sal ud, régimen subsidiado, indígenas, Colombia, La Guajira, wayuu.

Abstract

R ased on ethnographic research in two Wayuu communities of La Guajira, this article analyzes two aspects regarding the performance of indigenous representatives in the subsidized health care system: on the one hand, the given conditions and room for maneuvering their participation in order to carry out their functions; and on the other, the strategies employed by these representatives to guarantee access to health services. This study reveals one of the characteristics of multicultural systems: while general and inclusive at the regulatory level, they are inflexible at the local level where policies are implemented. Actors' strategies reveal the constraints imposed by the system on their performance as local agents. Nonetheless, the results of these strategies also depend on local institutional logics and socio-cultural dynamics.
\end{abstract}

KEY WORDS: Health system, subsidized regime, indigenous peoples, Colombia, Guajira, Wayuu.

Revista Colombiana de Antropología

Volumen 40 , enero-diciembre 2004, pp. $85 \cdot 21$ 


\section{INTRODUCCIÓN*}

D URANTE LA DÉCADA DE 1990, MÚLTIPLES PROCESOS ECONÓMICOS Y político-administrativos desembocaron en la reforma del estado colombiano, de sus instituciones y del tratamiento de sus ciudadanos. El reconocimiento de la diversi dad étnica y cultural del país supuso la formulación de leyes que promovieron la participación política de las minorías étnicas y que definieron sus derechos básicos ${ }^{1}$. Entre dichas minorías, los indígenas alcanzan a ser aproximadamente $2 \%$ de la población total colombiana, ocupando cerca de $25 \%$ del territorio nacional ${ }^{2}$.

La reforma del sector de la salud cambió la manera en que se atendía a la población indígena: antes de 1993 los servicios eran gratuitos y los proporcionaban los hospitales públicos ${ }^{3}$, y las acciones de sal ud pública eran ejercidas por las secretarías departamentales desal ud, los hospital es públicos y por al gunas direcciones

* Este artículo es el resultado de una investigación realizada gracias a una beca para jóvenes investigadores de la Alianza para la investigación en políticas y sistemas de salud asociada a la O rganización Mundial de la Salud (OMS).

1 Para estos grupos, el reconocimiento de la diversidad étnica y cultural se ha convertido en un espacio político de inclusión en el universo nacional. Las estrategias utilizadas por los wayuu para acceder al sistema de salud, participar en su funcionamiento y exigir la calidad de los servicios forman parte del proceso de reorganización política que busca el acceso a los bienes y servicios del estado.

2. Este $25 \%$ es una aproximación al total de la extensión de los territorios indígenas, resguardos o asentamientos, distribuidos por todo el país. Estos territorios van desde unas cuantas hasta cinco millones de hectáreas, para el más amplio en el Amazonas.

3El decreto 1811de 1990 estableció la gratuidad de los servicios de salud para los pueblos indígenas. Este decreto sigue vigente para los no afiliados y para los servicios no cubiertos por el plan obligatorio de salud subsidiado (PO S-S).

4. El término de entidades territoriales se utilizará en este artículo para hacer referencia a los municipios, departamentos y territorios indígenas que participan en las rentas nacionales. deasuntos indígenas. Con laley 100 de 1993 los indígenas se convirtieron en beneficiarios potencial es del régimen subsidiado de salud, pero también en grandes actores de su funcionamiento.

La constitución política de 1991 definió a los territorios indígenas como entidades territorial $\mathrm{es}^{4}$, al igual que a los departamentos, distritos y municipios. De esta manera, las diferentes poblaciones indígenas participan en las rentas nacional es medianteel sistema general de participaciones, Ilamado antes sistema de transferencias. En efecto, los gobiernos indígenas, es decir los cabildos y las autoridades tradicionales en tanto entidades públicas, adquirieron competencias -responsabilidades o funciones- relativas a la salud, la educación, el desarrollo y los servicios públicos. 
En tanto agentes local es ${ }^{5}$, los cabildos o las autoridades tradicionales deben garantizar las acciones de salud pública -prevención y promoción de salud, vigilancia epidemiológica y de riesgos ambiental es, etcétera-, la afiliación de sus poblaciones al régi men subsidiado y la calidad y adecuación cultural de los servicios. No obstante, a pesar de su nuevo estatus, todavía no gozan de autonomía política y financiera completa ${ }^{6}$, carencia que ha determinado en gran medida su rol en el sistema de salud, especialmente en el régimen subsidiado.

Los estudios sobre los sistemas de salud latinoamericanos exploran sus retos en términos de pobreza, capacidad financiera, objetivos de la salud pública y dela atención primaria, responsabilidades de los individuos y comuni dades sobre su salud, pero no mencionan Ias implicaciones de la diversidad étnica y cultural para estos sistemas (Londoño y Frenk, 2000). La literatura internacional se ha enfocado en la equidad y su lugar en las reformas sanitarias, señalando la participación comunitaria como el emento esencial para garantizar el acceso y la calidad de los servicios (Baum y Kahssay, 1997; OMS, 2000; Figueras et al., 2002; Nelson y Wright, 1997; Huff y Klir, 1999, Nazroo y Karlsen, 2001; Mooney, Jan y Wiseman, 2002). En este sentido, el desarrollo de sistemas locales de salud fue definido como el principio para el desarroIlo de la salud indígena (Alderete, 1999; OMS, 1999, OPS, 1993 1995 1997). Sin embargo, el rol de los gobiernos indígenas como agentes locales en el desempeño de estos sistemas ha recibido poca atención, pues por lo general sólo se les atribuye el rol de usuarios

5 Basados en el "principal-agent approach", Bossert y Beauvais (2002) definieron dos actores en los sistemas de salud: los "agentes principales" - los ministerios de salud y las instituciones estatales que regulan los sistemas descentralizados de salud-; y los "agentes locales" -gobiernos municipales y regionales, así como las oficinas descentralizadas o las instituciones autónomas que implementan las acciones definidas por los principales-. En este sentido, consideraremos a los gobiernos indígenas como agentes locales, pues participan en los procesos locales del sistema de salud.

6. Puesto que el proyecto de ordenamiento territorial con el que se conformarían las entidades territoriales indígenas (ETI) todavía no ha sido aprobado en el legislativo colombiano, el artículo 82 sobre los resguardos indígenas sigue vigente en la actualidad: "En tanto no sean constituidas las entidades territoriales indígenas, serán beneficiarios del sistema general de participaciones los resguardos indígenas legalmente constituidos y reportados por el Ministerio del Interior al Departamento Administrativo $\mathrm{Nacional}$ de Estadísticas, Dane, y al Departamento Nacional de Planeación en el año inmediatamente anterior a la vigencia para la cual se programan los recursos" (el subrayado es mío). La inversión de dichas participaciones debe "destinarse a satisfacer las necesidades básicas de salud incluyendo la afiliación al régimen subsidiado, educación preescolar, básica primaria y media, agua potable, vivienda y desarrollo agropecuario de la población indígena" (ley 715 de 2001). Adicionalmente, estas entidades territoriales pueden cofinanciar proyectos con el sector privado y otras dependencias del estado. 
o de "participantes" en la definición de los programas y, eventual mente, en su evaluación.

Los análisis sobre la reforma del sistema de salud colombiano se han concentrado en su financiación, la descentralización, la participación de los usuarios en su regulación y control, la calidad de los servicios y el acceso a los mismos (Celedón y Noé, 2000; Mosquera et al ., 2001; Plaza, Barona y Hearst, 2001; Jaramillo Pérez, 2001), y poco se ha publicado en relación con el rol y la participación de los indígenas en estos procesos. En cambio, la antropología médica ha trabajado ampliamente sobre los conceptos nativos y alternativos de salud, enfermedad y bienestar, los sistemas médicos nativos y su relación con los sistemas médicos occidentales (Pinzón et al., 1993 Stout y Col oma, 1993 Carrillo, 1996; Rossi, 1996; Puerta Silva, 1999). En general, este tipo de estudios señala la baja capacidad del sistema público para atender de ma-

7. Son pocos los trabajos que se han publicado sobre la planeación de los sistemas de salud para indígenas o sobre la formación de personal médico nativo; entre ellos, los más importantes son los de Juan G uevara G arzón (1998).

8. La participación indígena en el sistema de salud (artículos 2324 y 25 de la ley 691 de 2001) se ha establecido por medio de los siguientes mecanismos: la concertación, proceso basado en la ley 21de 1991 sobre consulta previa y concertación; la representatividad, mediante la presencia de un miembro de los pueblos indígenas en el consejo territorial de seguridad social en salud al que pertenezcan; y el control, haciendo parte de "la red de controladores del sistema" (ley 691 de 2001).

9. Este trabajo se basa en el trabajo de campo realizado en la guajira colombiana desde 1998, especialmente entre 2000, 2002 y 2003 Desde el enfoque de la antropología global, consideramos las estrategias utilizadas por los actores durante la implementación de las políticas sanitarias como un proceso de articulación de "lo local" con "lo global". En este sentido, la descripción de las experiencias de los representantes indígenas expone cómo los actores responden a ciertas condiciones impuestas globalmente. En este caso, las propiedades y límites del sistema de salud representan "lo global", mientras que el escenario constituido por los actores y sus estrategias, constituye "lo local" (Friedman, 2000; Ekholm-Friedman y Friedman, 2004). nera adecuada a los pacientes indígenas, sin profundizar sobre el papel de los indígenas como agentes locales del sistema de salud ${ }^{7}$.

Aunque la participación delos indígenas es cada vez más importante en las esferas regulativas del sistema de salud, la mayor parte de la legislación que le concierne en relación con las poblaciones indígenas ha sido definida sin mucha injerencia directa de sus representantes ${ }^{8}$. En esteescrito me concentraréen el funcionamiento del sistema en el nivel local y no en su regulación por parte de los actores principales.

Bajo la óptica de la antropología global, este artículo pretende comprender cómo se han desempeñado los representantes indígenas en su papel de agentes del sistema de salud en su implementación local, a partir dela experiencia de dos comunidades wayuu y de sus dirigentes ${ }^{9}$. Su propósito 
es, por un lado, identificar cuál es el contexto en el que tiene lugar la participación indígena en el sistema, es decir, cuáles son las "condiciones" impuestas sobre ellos para cumplir sus funciones e implementar las políticas local mente. Estas condiciones ejercen su influencia desde diferentes niveles, pues son los límites dentro de los que los agentes locales actúan. Entre ellas podemos mencionar la ideol ogía predomi nante en cuanto al lugar de las poblaciones indígenas en los escenarios nacional y local -reflejada en la legislación-; la dinámica propia del sistema de sal ud; el estado de la sal ud; y la situación socioeconómica, cultural y política de las poblaciones locales.

Por otro lado, se trata de describir las estrategias ${ }^{10}$ usadas por los gobiernos indígenas para cumplir los roles asignados por el sistema, en cuanto a la planeación y ejecución de acciones de salud pública y al funcionamiento del régi men subsidiado. Entre las estrategias observadas en La Guajira pueden mencionarse las negociaciones con los otros gobiernos locales, con las aseguradoras y con otras entidades públicas y privadas; la utilización de recursos jurídicos; la formación de miembros de la comunidad como agentes de salud; y la creación de sus propias aseguradoras.

Por úl timo, la escogencia delas estrategias usadas por los representantes indígenas se relaciona10. El conjunto de acciones utilizado por los agentes para lograr sus objetivos.

11 Espacios de acción por fuera de la hegemonía del sistema, es decir, los vacíos de éste aprovechados por los agentes para promover sus intereses. rá con las condiciones impuestas por el sistema - los márgenes de maniobra ${ }^{11}$ - y con las lógi cas y prácticas locales, ya que localmente se manifiesta la disposición de las lógicas y prácticas institucionales frente a las estrategias utilizadas por los representantes indígenas.

\section{LAS CONDICIONES}

\section{El sistema de salud colombiano y los indígenas}

E N 1993, EL GOBIERNO COLOMBIANO EMPEZÓ LA REFORMA DE SU SISTEMA - de salud con la creación del sistema general de seguridad social en salud (sGSSS), en el que se separaron las funciones de re gulación y financiación, controladas por el estado, y las de 
articulación y provisión, abiertas al sector privado (Vargas, 1997; Movimiento por la Salud Pública, 1998). Desde entonces, el sistema se administra de manera descentralizada, ya que el gobierno central ha transferido la mayoría de las competencias y los recursos a los gobi ernos departamentales y municipales. Su propósito fundamental es el cubrimiento de toda la población con equidad y cal idad por medio de dos regímenes complementarios, el contributivo y el subsidiado, de acuerdo con un esquema de redistribución del ingreso y de sol idaridad ${ }^{12}$.

Cada uno de los regímenes se dotó de una oferta de servicios específica: el plan obligatorio de salud (POS), para el régimen contributivo, y el plan obligatorio de salud subsidiado (POS-S). El último, más reducido, depende del perfil epidemiológico y de la vulnerabilidad de la población de la zona. Mientras el primero es administrado por las entidades promotoras de salud (EPS), el segundo lo es por las administradoras del régimen subsidiado (ARS), que contratan a los proveedores -instituciones prestadoras de salud (IPS), públicas y privadas-. Al primer régimen se afilian los asal ariados que pueden pagar su seguro, y al segundo los sectores poblacional es calificados como "pobres" o vul nerables ${ }^{13}$, además de los "grupos especiales" -indígenas, ni ños abandonados, desplazados y desmovilizados-. Las "personas vinculadas al sistema", son las que no están afilia-

2. El régimen subsidiado es financiado con un porcentaje del pago de los afiliados al contributivo, las rentas nacionales, los recursos propios de las entidades territoriales, los recursos de los juegos y loterías y las regalías de los nuevos yacimientos petroleros. El esquema de redistribución supone la universalidad de los beneficios mediante la protección del asegurado y su núcleo familiar.

13 Personas pertenecientes al nivel I y II de la clasificación del sistema de identificación y clasificación de potenciales beneficiarios para los programas sociales (Sisbén). das a ninguno de los dos regímenes, y que son atendidas por IPS públicas y privadas bajo un esquema de demanda contratado por los gobiernos local es y departamentales.

La ley 60 de 1993regl amentó los artículos de la constitución en materia de competencias y recursos descentralizados del sector salud, y la ley 100 de 1993 , sobre la reforma de la seguridad social en salud, del egó a los municipios y departamentos la administración del régimen subsidiado (Jaramillo Pérez, 2002). Además, las entidades territoriales deben diseñar sus planes de atención básica (PAB), en los que se identifica el estado de sal ud de las poblaciones, los factores ambientales y sociales de riesgo y se diseñan las acciones y proyectos correspondientes. 
Por su parte, la ley 715 de 2001 redefinió los recursos y las competencias de las entidades territoriales y dictó las disposiciones para organizar la prestación de los servicios de educación y salud y para adjudicar los recursos dirigidos al aseguramiento de la población vulnerable, la atención de salud de los no afiliados y las acciones de salud pública.

Mediante la ley 691 de 2001 se reglamentó la participación ${ }^{14}$ de los grupos étnicos en el SGSSS; al lí se confirmaron los principios que deben regir la planeación y las acciones de salud pública y los servicios de sal ud subsidiada: el respeto a la cultura, la articulación de las medicinas indígenas con la occidental, el fortal ecimiento de los promotores de salud indígenas como articuladores de los sistemas de salud, la gratuidad de la atención, la consulta previa a toda acción relacionada con salud indígena, la participación de las comunidades en el seguimiento y control de dichas acciones, y la existencia de interlocutores permanentes en los departamentos y el Ministerio para atender a las comunidades ${ }^{15}$.

De acuerdo con esta legislación especial para los indígenas, Ios municipios y departamentos son responsables de su afiliación al régimen subsidiado. A partir de "censos actualizados" presentados por los gobiernos indígenas, los municipios asignan un número determi nado de afiliaciones cada año, con el objetivo de aumentar progresi vamente la cobertura. Los munici pios y los gobiernos indígenas contratan entonces las aseguradoras ${ }^{16}$ (ARS), que, a su vez, contratan los servicios médicos con las IPS.

Las ARS indígenas son las únicas autorizadas para efectuar acciones de prevención y promoción para los indígenas, financiadas por los municipios y departamentos. En la figura 1 (véase infra página 101), pueden distinguirse los procesos del sistema subsidiado para los indígenas -rayados en gris- de los otros procesos del sistema general de salud, a pesar de que están íntimamente ligados. Antes de

14. En la terminología legislativa, "participación" se utiliza para referirse a dos fenómenos distintos: el primero, la participación como autonomía, capacidad y poder político de los individuos y grupos para intervenir en los procesos de toma de decisiones y de desarrollo de políticas. El segundo se refiere a la participación como el concurso de las entidades territoriales en los ingresos corrientes de la nación, así como también en las competencias y funciones del sistema de salud.

15 Esta ley se basa en el principio de la consulta y concertación (ley 21 de 1991) y el respeto de la autonomía de los pueblos indígenas (constitución política).

16. Según la legislación, los usuarios tienen el derecho de escoger su aseguradora. En el caso del régimen subsidiado, los municipios citan a las comunidades para escogerlas colectivamente. 
Roles y estrategias de los gobiernos indígenas en el sistema de salud

profundizar más en el funcionamiento del sistema es necesario conocer su estado en el departamento de La Guajira.

\section{El departamento}

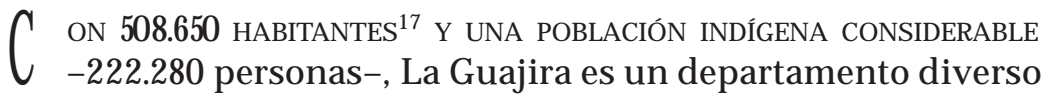
cultural y étnicamente, donde conviven indígenas pertenecientes a cuatro etnias (véase el recuadro página 94) y comunidades afrocolombianas, mestizos y árabes (286.379 personas) ${ }^{18}$; es rico en recursos energéticos, pero no está muy industrial izado; y tiene altos índices de pobreza y servicios públicos deficientes.

Está dividido en quince municipios y cien corregimientos e inspecciones de policía, y los al cal des, la autoridad municipal, son el egi dos mediante voto popular. Cuenta con uno de los resguardos más extensos del país, además de otros quince creados en los últimos veinte años.

De acuerdo con sus características geográficas y socioeconómicas, el departamento se divide en tres regiones: la alta, la media y la baja Guajira -o el sur-. En la baja se ubica El Cerrejón, una de las minas de carbón a cielo abierto más grandes del mun-

17. Proyección del censo 2003 Plan de desarrollo departamental 2004-2007.

18. En los documentos institucionales, la población está dividida en "cuatro grupos étnicos" criollos (personas de origen blanco, negro y extranjeros: árabes, antillanos y europeos), wayuus, koguis, arsarios (o wiwa) y arhuacos (o ijka).

19. Las poblaciones wayuu que todavía no poseen un título de propiedad colectiva de tierras son llamadas "asentamientos". Por la inexistencia del "título", estas comunidades no participan de los ingresos corrientes de la nación y, por tanto, dependen completamente de los municipios.

20. Las regalías de las explotaciones mineras se distribuyen entre los resguardos, los municipios y los departamentos con jurisdicción sobre el yacimiento. Además, un porcentaje se destina al Fondo Nacional de Regalías. do. También se expl otan otros recursos como el gas natural, la sal marina, el yeso y el talco. El complejo minero deEl Cerrejón -mina, vía férrea, carretera y puerto- tiene una influencia importante sobreun sector del resguardo wayuu de la al ta y media Guajira, y sobre por lo menos veinte resguardos y asentamientos wayuu de la baja ${ }^{19}$ (véase el mapa).

Aunque es uno de los departamentos del país que más regalías reci be ${ }^{20}$, más dela mitad de su población vive por debajo de la línea de la pobreza. En efecto, de 508.650 habitantes, cerca de $63 \%$ 


\section{Revista Colombiana \\ de Antropología

\section{Resguardos de La GuajIRA}

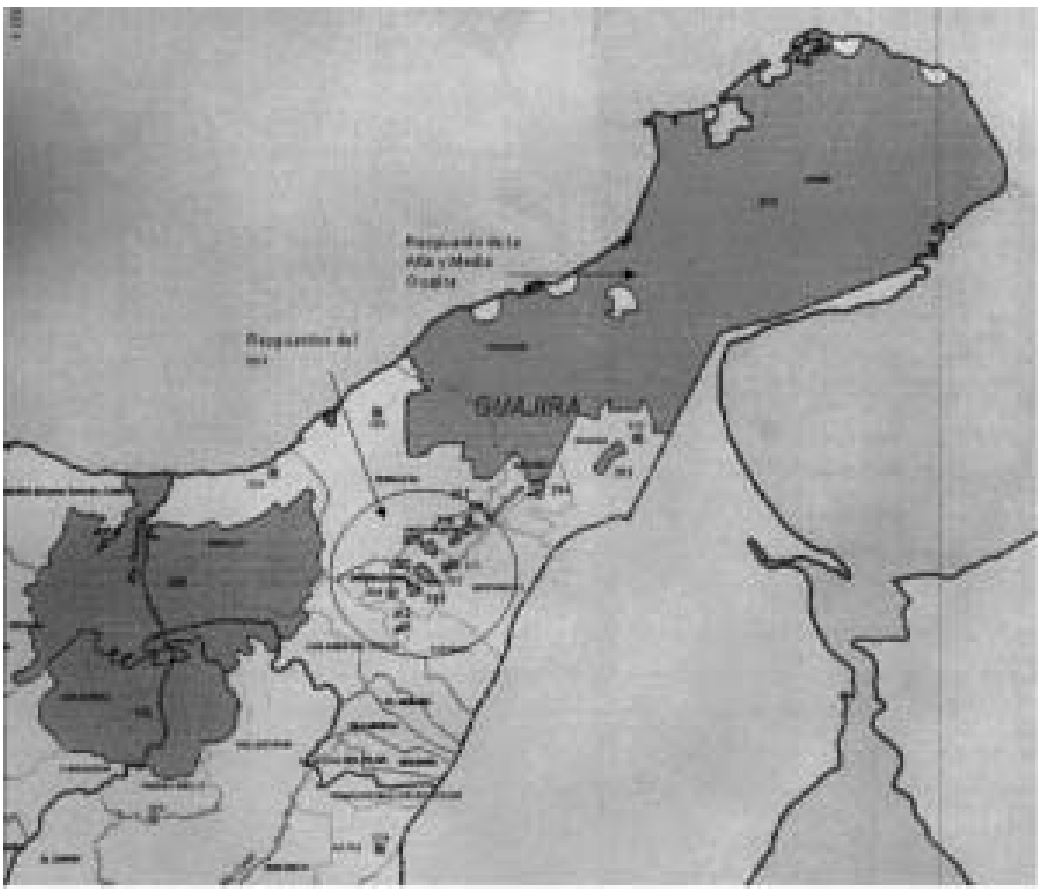

Fuente: tomado de Igac. "Mapa de resguardos indígenas". 2003

es considerado por las autoridades departamental es como "pobre y vul nerable" o perteneciente a un "grupo especial"21. Sesenta y uno por ciento de su población es urbana, y la rural 39\% -en su mayoríaubicadaen el resguardo de la al ta y media Guajira-. La densidad demográfica aumenta de norte a sur: de 7 habitantes por $\mathrm{km}^{2}$ en la alta, a 79 en el sur. Los sistemas viales, lastelecomunicaciones, la electricidad, el acueducto y alcantarillado son ineficientes o inexistentes.

En la página siguiente pueden verse, resumidas, las principal es características socioétnicas y admi nistrativas de las áreas con títulos de propiedad colectiva de La Guajira.

21 La inclusión de la población pobre y vulnerable y de los grupos especiales en el mimo porcentaje responde a la clasificación que se realiza dentro del sistema de salud para identificar los potenciales beneficiarios del régimen subsidiado. Esta clasificación tiene, por supuesto, implicaciones importantes en la respuesta de las necesidades y expectativas de los usuarios. Adicionalmente, una equivalencia implícita entre las poblaciones beneficiarias del régimen subsidiado se establece sin ninguna correspondencia con sus condiciones reales y las diferencias entre ellas. En este sentido, es urgente una discusión más amplia sobre la diferenciación entre los potenciales beneficiarios del régimen subsidiado, pero trasciende el objeto de este artículo. 


\section{ETNIAS}

Wayuus: 38,43\%; kogui: 3\%; arsarios (wiwa) y arhuaco (ijka): $1 \%$.

\section{ENTIDADES TERRITORIALES}

- Con títulos de propiedad colectiva (2002)

- Quince resguardos wayuu (aprox. 52\% del área total del de partamento $=20.848 \mathrm{~km}^{2}$ ).

- Un resguardo kogui-mal ayo-arhuaco (Sierra Nevada de Santa Marta).

- Sin títulos de tierra

- Quince-veinte asentamientos y barrios en los cascos urbanos o sus proximidades.

\section{RePRESENTANTES LEGALES}

Son representantes legales los caciques -como son Ilamados los gobernadores o jefes de los cabil dos- y las autoridades tradicionales, o, en su efecto, otros miembros de la comunidad nombrados para desempeñar los cargos administrativos.

\section{TIPOS DE GOBIERNO}

- Resguardos del sur

Cabildos: "Es una entidad pública especial, cuyos integrantes son miembros de una comuni dad indígena, el egidos y reconocidos por ésta (...) cuya función es representar legalmente a la comunidad, ejercer la autoridad y real izar actividades [adecuadas y de acuerdo a la cultura propia]". Integrantes: un jefe (cacique), un "segundo", un secretario, un fiscal, un tesorero, etcétera. Administran los recursos de la entidad territorial y ejecutan los planes de desarrollo y de salud.

- Resguardo de la alta y media Guajira

Autoridades tradicionales: "Son los miembros de una comunidad indígena que ejercen dentro de la estructura propia de la respectiva cultura, un poder de organización, gobierno, gestión o control social (poseen la mi sma representación y atribuciones que corresponde a los cabildos indígenas)".

Asociaciones de autoridades tradicionales: entidades públicas que representan y congregan varias autoridades tradicionales y sus comunidades. En general, se eligen uno o dos representantes legal es. 


\section{El estado de la sal ud y (de) los servicios en La Guaji ra ${ }^{22}$}

A INFECCIÓN RESPIRATORIA AGUDA (IRA) ES LA PRIMERA CAUSA DE MORBIlidad por consulta externa, seguida por las enfermedades de transmisión sexual, las enteritis y otras enfermedades diarreicas, las enfermedades de la piel y del tejido subcutáneo. Aunque se reconoce que estas últimas afectan con mayor frecuencia a los indígenas, no se han elaborado perfiles epidemiológicos por pertenencia étnica ni se han relacionado las causas de morbilidad con factores de riesgo ambientales o estilos de vida.

A pesar de la reforma, el proceso de modernización de las entidades públicas y la descentralización, La Guajira muestra deficiencias preocupantes en la capacidad de sus municipios, ARS eIPS para cumplir con sus competencias, fundamental mente por las cifras de pobreza y vulnerabilidad mencionadas, además de los graves problemas financieros y la corrupción, comunes en todo el territorio nacional.

En La Guajira existen tres instituciones de segundo nivel, catorce IPS públicas de primer nivel, veintinueve centros de salud y noventa y nueve puestos de salud, con un total de 438 camas -314 públicas y 124 privadas-, esto es, 0,9 camas por cada 1000 habitantes en el departamento, indicador muy por debajo del nacional, que es de 38 por 1000. Hay, además, once ARS -de las cuales, en 2002, dos eran indígenas- y nueve EPS.

A octubre de 2003 sólo estaba afiliado $65 \%{ }^{23}$ de los 331.182 beneficiarios potenciales del régimen subsidiado; de ese $65 \%$ (215.268), 110.732 (51\%) era indígena. La población vinculada era, entonces, casi $3 \%$ del total dela población pobre y vulnerable.

22. Datos tomados del plan de desarrollo departamental 2004-2007.

23 Ha habido avances importantes en el aseguramiento: en 2001 sólo $51 \%$ estaba afiliado. En dos años la cobertura se amplió en más de $10 \%$.

Al tratar deidentificar los problemas deaseguramiento, en 2001 , la Secretaría Departamental de Sal ud señal aba los siguientes:

(...) el número de actores e instancias que participan en él y el poco control que se tiene en el manejo de los recursos y programas, cabe destacar entreestos el sistema deinformación, el cual no es confiable y no permi te saber a ciencia cierta cuánta es la población vinculada y afiliada (...) la falta de recursos financieros y tecnológicos que 
impiden ampliar las coberturas de afiliación al régi men subsidiado y ofrecer mejores servicios (...) la falta de recurso humano que dificulta el proceso de inspección, vigilancia y control del sistema (PAB departamental 2001).

En 2003, la administración departamental coincidía en que las bases de datos seguían siendo el principal problema en el aseguramiento, "especialmente en las comunidades indígenas, debido a que no poseen identificación clara y en la población se encuentra gran cantidad de multiafiliaciones y duplicidades que son muy difíciles de corroborar" (Gobernación de La Guajira, 2004).

24. Las aseguradoras raras veces utilizan los centros y puestos de salud de los resguardos y asentamientos, pues prefieren prestar ellas mismas los servicios 0 , en su defecto, contratar a las instituciones de la red pública en los cascos urbanos. Así, las aseguradoras tienen sus propias IPS y desplazan de la provisión a las IPS públicas, sin mejorar necesariamente la calidad de los servicios.

Aunque todos los hospitales de la red pública se han transformado en empresas sociales del estado (ESE-IPS), no han escapado a la crisis hospital aria nacional -agravada desde 1997-. A estacrisis sesumala proliferación de IPs privadas o pertenecientes a las mismas aseguradoras ${ }^{24}$ y la eliminación de su competencia en la ejecución de las acciones de salud pública para las poblaciones indígenas.

se puede buscar cuántas EPS se han creado después de la ley [ 100 de 1993]; una casa con un consultorio, un médico y una enfermera; las ARS pa' salirse de ese problema [promoción y prevención] contrataban con la red pública y los hospitales que tenían red de promotores (...) pero ahora, ahora habrá que negociar con las alcaldías y las alcaldías habitualmente tienen [sus propios promotores]; por lo menos la de Uribia no tiene una secretaría de salud operante, hay un secretario sin computador con una secretaria que desconoce la reglamentación, que no tiene los censos, no sabe cómo es la consultación [en el hospital ]; aquí nos ha tocado arreglar mil veces esa vaina porque cada nueva contratación [con el municipio] es el problema porque [ellos] no tienen [las] bases de datos [de las consultaciones que nosotros les mandamos] (...) (médico en La Guajira, abril de 2002).

En este sentido, el acceso y la calidad de los servicios son los más afectados, especialmente en términos de la adecuación intercultural, puesto que los hospital es que habían avanzado en este senti do se vieron afectados por la crisis financiera, como es el caso de los de Manaurey Uribia. Sól o el hospital de 


\begin{tabular}{r|r}
$\begin{array}{r}\text { Revista Colombiana } \\
\text { de Antropología }\end{array}$ & 97 \\
volumen 40, enero-diciembre 2004 &
\end{tabular}

Nazareth ${ }^{25}$ y el centro desalud de la Casa indígena de Riohacha siguen funcionando con ese espíritu.

Además, los planes deatención básica de La Guajira no contienen acciones que correspondan a las condiciones sociales, culturales, económicas y ambiental es propias del departamento. Así, por ejemplo, no tienen en cuenta los riesgos a la salud causados por la explotación minera. En la planeación no establecen, tampoco, la relación entre el funcionamiento del sistema sanitario y las características sociodemográficas y culturales de las poblaciones. Finalmente, estos planes no identifican las consecuencias que pueden tener las condiciones geográficas y climáticas en la salud de los habitantes.

\section{LOS ACTORES}

ON EL RIESGO DE SER ESQUEMÁTICA, LA SIGUIENTE DESCRIPCIÓN DE las dinámi cas wayuu brinda al gunos el ementos de comprensión para sustentar las apreciaciones que se harán más adeIante, concernientes a las estrategias que usan los representantes indígenas en el sistema.

Los wayuu habitan la guajira colombiana y venezolana, sumando actual mente cerca de 300 mil, en una región fronteriza que cuenta con extensas costas, las cual es han favorecido desde el siglo dieciséis el comercio legal y el contrabando. La cría de ganado mayor fue importante hasta el siglo diecinueve en las sabanas del río Ranchería y en al gunas sabanas de la media y la al ta Guajira. Pero por diversas razones -que no es del caso tratar en este artículo-, para la mayoría de los wayuu la cría de ganado menor se convirtió luego en la actividad económica más importante, junto con el comercio.
25 El hospital de Nazareth (alta Guajira) atiende cerca de 3 mil personas, en una ex-

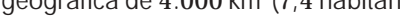
afiliado al régimen subsidiado (datos de 2001). A pesar de los graves problemas financieros por los que atraviesa, sus mayores Iogre basan en la adecuación cultural de nes de prevención y promoción de la salud; la formación y capacitación de promotores sor la región; acciones coordinadas con (ricional; el mantenimiento de didos perma territorio; y la infraestructura del hospital que permite a los pacientes cumplir con los tratamientos en un ambiente muy cercano al de su cotidianidad (trabajo de campo, 2002). 
La baja Guajira, o "el sur", se caracteriza por ser una zona de sabanas productivas para la cría de ganado y para la agricultura, y allí se encuentran local izados la mayoría de los municipios y delos resguardos indígenas. Al gunos resguardos y barrios urbanos wayuu cuentan con los servicios de agua y luz. A demás del pastoreo y la pequeña agricultura, el trabajo asal ariado y jornalero también son actividades propias suyas. En esta región, la presión territorial es fuerte y la densidad demográfica alta. A pesar de la creación de varios resguardos wayuu en los últimos veinte años, las comunidades han perdi do acceso a la tierra por los fuertes procesos de migración y colonización, y por la presencia del complejo minero, los cultivos de arroz y la ganadería extensiva.

El acceso limi tado a las tierras, así como la desertificación y el agotamiento de los recursos, han dado como resultado la disminución delos rebaños y de la práctica del pastoreo en general . La migración hacia los cascos urbanos se rel aciona con los factores anteriores, pero también con otros aspectos como la necesidad de atención médica, de centros escolares y de trabajo ${ }^{26}$. Desde hace unos años hay desplazamientos de mayor envergadura, relacionados con el conflicto nacional. A mediados de 2003, grupos armados ilegales ocuparon algunos resguardos de la baja Guajira, y a principios de 2004 desplazaron a al gunos de los habitantes de bahía Portete.

En la alta y media Guajira, Ios wayuu gozan de un control territorial relativo. Se dedican al pastoreo, la pesca y el comercio, complementando estas actividades con los ingresos de algunos de los miembros de la familia extensa que se trasladan a las ciudades a estudiar y trabajar, especialmente a Riohacha, Uribia, Maicao y Maracaibo (Venezuela).

Aunque con ciertas variaciones, Ios wayuu se rigen básicamente por un sistema de parentesco matrilineal y de habitación matrilocal. Los núcleos más importantes de la sociedad

26. En alguna medida, los conflictos entre clanes han obligado también a algunas familias a trasladarse a los centros urbanos.

27. Conjuntos habitacionales constituidos por habitaciones y sus cocinas, enramadas, corrales, fuentes de agua - pozos, molinos, jagüeyes, etcétera-, zonas de pastoreo, rozas y, algunas veces, un cementerio. están compuestos por familias extensas, quese distribuyen territorialmente en rancherías ${ }^{27}$ o habitan en las cabeceras municipales, por lo general en barrios en donde predomina la población wayuu. Las estructuras deautoridad y de toma de decisiones es- 
tán muy determinadas por estesistema social, aunque otros factores influyen en el acceso al poder. Los parientes paternos son referentes importantes para la herencia, las al ianzas de guerra, algunos cobros y compensaciones, y en la actualidad son cada vez más determinantes para el acceso a roles políticos y económicos por fuera de las comunidades indígenas.

La pertenencia familiar y territorial marca predominantemente las respuestas colectivas de los wayuu. En principio, cada familia extensa es autónoma para tomar las decisiones concernientes a sus miembros. Cada grupo familiar reconoce una figura mascul ina dominante: el alaüla (tío materno, viejo o jefe). Pero también hay mujeres reconocidas por su experiencia, consideradas como autoridades tradicionales. Entre la al ta y la baja Guajira hay grandes diferencias en cuanto al rol público de las mujeres: es más frecuente que ellas sean las representantes o Ias líderes en la al ta y la media Guaji ra, mientras que los hombres predominan en el espacio político del sur ${ }^{28}$.

Al gunos referentes territoriales tienen que ver con los cementerios, pero también con el uso y la permanencia en los territorios. A partir de los años 1970 fue evidente la urgencia de obtener títulos colectivos de tierra, que se hicieron efectivos en las décadas de 1980 y 1990 . Después de la bonanza marimbera -producción y tráfico de marihuana- en el pie de monte delaSierra Nevada deSanta Marta, los wayuu del sur empe-

28. El término "líder" es una categoría local que designa a la persona que representa una comunidad y que se caracteriza por un conjunto de atributos específicos que determinan los resultados de las diligencias que emprende a favor de la comunidad. Actualmente es un término despectivo por la trivialización del rol de los líderes.

zaron a demandar derechos

territorial es en respuesta a la ampliación de haciendas ganaderas y arroceras, y al crecimiento urbano. Pero fue a principios de los años 1980, durante la construcción de la infraestructura minera, cuando los conflictos territoriales y las demandas de reconocimiento de identidad étnica se activaron, motivados por la invisibilización institucional del "carácter wayuu" de las poblaciones que habitaban estas áreas.

Desde entonces, "la ocupación del territorio y la presencia ancestral", y luego los títulos colectivos de tierras, han sido los pilares de la articulación política delas comunidades wayuu con el estado colombiano. A partir del carácter de "resguardo" y, eventual mente, del de "asentamiento", las comunidades han logrado su reconocimi ento y el derecho a insertarse como agentes lo- 
cal es en variadas funciones públicas, específicamente en el funcionamiento del sistema de salud.

\section{LOS ROLES Y LAS ESTRATEGIAS}

\section{Los cabi Idos y asociaciones como agentes locales \\ COMPETENCIAS O ROLES}

EN EL SISTEMA DE SALUd COLOMBIANO, EL CUMPLIMIENTO DE LAS COMPEtencias de los gobiernos indígenas está todavía en transición, pues sus funciones administrativas están subordinadas a las de las alcal días y gobernaciones, principalmente en la ejecución de los presupuestos.

Los municipios son responsables de la afiliación de la población pobrey de los indígenas al régimen subsi diado. A las personas vinculadas al sistema deben garantizarles la prestación de servicios bajo el modelo de la demanda. Como mencionamos antes, el municipio o el departamento contrata a las ARS y éstas contratan a las IPS para la prestación de los servicios. En la figura 1 se ve cómo los otros procesos del sistema de salud se adicionan a los que ya conocemos del régimen subsidiado.

El funcionamiento del sistema de salud está constituido por una serie de procesos en los que los diferentes actores tienen roles más o menos precisos. Los cuadros grises en la figura 1 representan las fases en las que los gobiernos indígenas tienen injerencia y/o competencia. Aquellos cuyos marcos están puntuados y se ubican entre dos o más actores representan procesos en los que las estrategias de los gobiernos indígenas se evidencian con mayor claridad.

\section{LOS CASOS: UN CABILDO Y UNA ASOCIACIÓN DE AUTORIDADES TRADICIONALES}

ESTE TRABAJO ANALIZA LAS EXPERIENCIAS DE DOS GOBIERNOS WAYUU, UN cabildo y una asociación de autoridades tradicionales, ubicados el primero en el sur de La Guajira y la segunda en la alta Guajira. Tanto el resguardo como la asociación conglomeran 


\section{FIGURA 1}

EL SISTEMA DE SALUD PARA INDÍGENAS

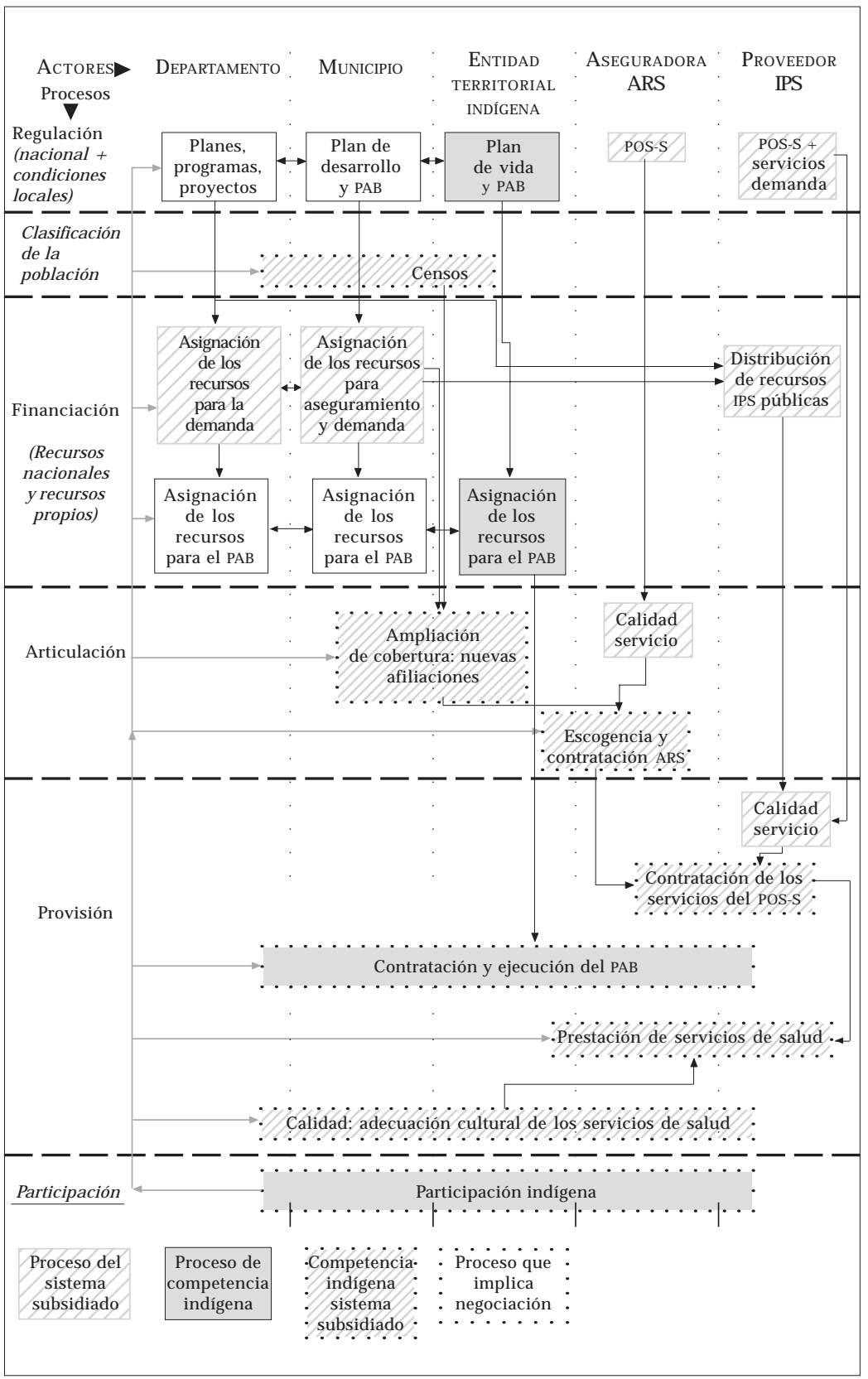


cuatro comunidades wayuu -conjuntos diferenciados de rancherías-. En total, sus poblaciones oscilan entre mil y mil trescientas personas. El resguardo tiene una extensión aproximada de 957 hectáreas, mientras que no se tienen datos de la extensión territorial ocupada por las comunidades asociadas de la alta ${ }^{29}$. Las funciones de cada uno de estos gobiernos las cumple, en el caso del resguardo, el cacique, y en el de la asociación, dos representantes legales ${ }^{30}$.

El cacique es un hombre adulto -aproximadamente 50-55 años- con amplia experiencia en la arena política regional y nacional. La representante legal es una mujer, de la misma edad, proveniente de una de las familias más influyentes de la región y de reconocido liderazgo. Ambos han sido el egidos sucesivamente desde comienzos de la década de 1990, de manera democrática, en asambleas comunales, y son líderes con amplia trayectoria política en La Guajira. Él inició su vida política en

29. El resguardo de la alta y media Guajira tiene una extensión aproximada de un millón de hectáreas.

30. Se trata de dos primos: un hombre y una mujer. La experiencia de la mujer es la que describimos en este artículo.

31. A comienzos de la década de 1990 se crearon otras organizaciones indígenas, y Yanama perdió representatividad de los intereses de los wayuu como colectividad. las juntas deacción comunal y en los sindicatos mineros, y ella comenzó su experiencia en Yanama, la primera organización wayuu de La Guajira, mediadora entre las comunidades indígenas y la compañía minera de El Cerrejón ${ }^{31}$.

El resguardo del sur cuenta, gracias a los proyectos de coinversión, con servicios de electricidad, acueducto y telefonía satelital, y con facilidades escolares y sanitarias. Así mismo, se ha "saneado" -mediante la legal ización de tierras ocupadas y el desal ojo de personas externas a la comunidad-, ampliando las zonas de producción ganadera y de agricultura. Fue el primero en definir un plan de vida -plan de desarrollo- de tres años. Los habitantes de este resguardo se transportan fácilmente al casco urbano, a quince minutos en automóvil. Dentro del mismo se trasladan por pequeños carreteables, en bicicl etas y motos. Con presencia permanente de una enfermera profesional, el centro de salud también al oja una vez por semana a un médico y a un odontólogo. Además, hay tres promotores y/o educadores de salud.

Las cuatro comunidades que conforman la asociación de la alta Guajira se encuentran dispersas en las inmediaciones de bahía Portete, en la jurisdicción de Uribia, a tres-cuatro horas 
en automóvil. Con baja densidad demográfica, las rancherías están dispersas en una amplia zona de las costas y de las sabanas internas. Trasladarse al pueblo es difícil, y entre las rancherías el camino se hace a pie, en bicicleta o en al gún vehículo en tránsito. No hay servicios de electricidad ni de acueducto. La asociación presentacadaañoalaadministración municipal un plan de inversión, con el cual ha cofinanciado la compra de un carrotanque de agua -fuera de servicio en ocasiones-, dos plantas desalinizadoras, botes de pesca y equipos de refrigeración, el mejorami ento de la calidad de los tejidos y programas de nutrición y de asistencia a los ancianos.

A raíz de una epidemia de cólera, la asociación tramitó la construcción de un centro de salud, que nunca fue equi pado ni utilizado completamente. El proyecto de la representante legal es reconstruirlo y dotarlo de los equipos necesarios, pues en la actual idad está deteriorado y desmantel ado ${ }^{32}$. En los últimos años, la asociación no ha podi do contratar personal médico para el centro de salud. A pesar detener una promotora de salud, ésta no permanece allí, pues se traslada por todas las rancherías.

32. Después de la incursión paramilitar de abril de 2004 no es posible saber cuál será la suerte de estos planes.

La población del resguardo está afiliada al régimen subsi diado en $90 \%$, mientras que no se tienen datos precisos de los miembros de la asociación - pueden ser cerca de 30\%-. En ninguno de Ios dos casos, las ARS contratadas ofrecen sus servicios en la localidad ni utilizan los centros de salud existentes, por lo que los pacientes deben trasl adarse a los centros urbanos. En el caso del resguardo esto no es muy difícil, por la cercanía y ciertas facilidades de transporte. En cambio, los miembros de la asociación tienen que desplazarse hasta Uribia, Maicao, Riohacha - Valledupar para recibir atención médica, lo que implica esfuerzos considerables, razón por la cual, en la mayoría de las ocasiones, prefieren tratar de curar al paciente de forma casera o tradicional.

Cuando el caso es grave se trasladan a los centros urbanos pero no siempre tienen sus carnés de beneficiarios por lo que son atendidos bajo el sistema de la demanda -para personas vinculadas- o pagan por los servicios. Los usuarios del resguardo tienen también problemas constantes de identificación en el momento de pedir atención médica o de solicitar los medicamentos. 
Las acciones desal ud pública correspondientes a estas comunidades son responsabilidad del departamento y de los municipios. Sin embargo, el resguardo es menos dependiente, puesto que tiene su propio PAB, cofinanciado por él y el departamento. En ninguno de los dos casos se tienen en cuenta los riesgos ambientales generales o los relacionados con la explotación minera o portuaria, y los servicios de salud tampoco son adecuados cultural mente, a pesar de que en el caso del resguardo Ia ARS contratada es indígena.

\section{Las estrategias de los gobiernos indígenas}

a Secretaría departamental de salud destaca la baja participaL ción de los usuarios como aspecto negativo en el funcionamiento del sistema sanitario. La reforma de 1993 estableció varios mecanismos, como la participación en las juntas directivas de hospitales y EPS, las veedurías ciudadanas y las asociaciones y alianzas de usuarios. Aun cuando esos espacios pretenden servir como mecanismos de control y evaluación de la calidad y el acceso, y se dirigen a la adaptación de las políticas y programas de salud a las necesidades, expectativas y condiciones de cada contexto, este nivel de participación ciudadana es todavía incipiente. Las siguientes son al gunas razones sugeridas al respecto por la entidad departamental:

(...) la falta de compromiso de las autoridades del nivel local y departamental, la poca aceptación institucional frente a las políticas democráticas y de participación, la falta de conocimiento, capacidad organizativa, degestión social de la comunidad quele permitan a estas resolver los problemas que la afecten (...) [los procesos de participación social] sehan debi litado debi do a la falta de asistencia técnica desdela secretaría departamental por las diversas reestructuraciones asumi das (PAB departamental 2001).

Pero, como hemos visto, la participación de los gobiernos indígenas en el sistema de sal ud no sól o está inscrita en estos mecanismos, sino que se acerca a la de los departamentos y municipios. Para cumplir con el desarrollo de la salud de sus comunidades, los gobiernos locales utilizan variadas estrategi as para ampliar la cobertura del aseguramiento, ejecutar acciones 
de salud pública, garantizar el acceso de sus habitantes a los servicios médicos y, finalmente, exigir la calidad y adecuación de los servicios de salud. Dichas estrategias pueden clasificarse en tres grandes tipos: negociaciones y transacciones; utilización de recursos jurídicos; y, finalmente, la formación de personal médico nativo y la creación de sus propias ARS.

\section{NEgociaciones Y TRANSACCIONES}

CON EL PROPÓSITO DE MEJORAR LA SALUD DE SUS COMUNIDADES Y GARANTIzar el acceso a los servicios, los representantes indígenas emprenden negociaciones con los otros gobiernos locales o con las aseguradoras. Aunque la corrupción es un elemento clave para la comprensión de la materia que estamos tratando, no lo desarrollaremos en este artículo pues es necesario profundizar más en su análisis ${ }^{33}$.

En el caso del resguardo, las decisiones relacionadas con la salud y con otros aspectos de la vida comunitaria se toman en asambleas generales.

(...) seconvocaaunareunión por parte del cacique (...) quien centraliza toda la información. Se hacen asambleas amplias para las cuales se convoca a mujeres, ancianos, auto- ridades tradicionales, jóvenes, etcétera. El cacique hace una introducción en lenguaal temaparael cual seconvocó. A veces los asistentes responden, asienten, confirman, pero lo dejan hablar hasta que termina. Luego se exponeel orden del díay seprocedea hacer las intervenciones. Se motiva quelagenteparticipey expreseloque está pensando y sus experiencias. Quejas y reclamos, aportes, problemas (...) Se plantean soluciones por parte de la mesa que dirige la reunión. Y entonces la gente refuta, hasta que se Ilega a un acuerdo. Es recurrente e Ilamado a pasar las cosas por escrito (...) las quejas, las soluciones, todo
33 Podemos presentar, sin embargo, algunas ideas útiles para un análisis posterior. La corrupción es una de las prácticas más comunes en las estrategias utilizadas por los actores. No obstante, puede ser considerada también como una condición estructural de las negociaciones y transacciones que éstos emprenden. La corrupción es una práctica institucionalizada que toma diversas formas, pero que resulta, por un lado, en beneficios económicos para las partes negociadoras: sea el famoso $10 \%$, sea la escogencia de los contratistas, sea la ARS elegida. Por otro lado, puede resultar en beneficios políticos y sociales, traducidos en el aumento del estatus social, en el establecimiento de alianzas, en el acceso a posiciones políticas, apoyo electoral, etcétera. Además, la conexión entre la corrupción y la escogencia de los proyectos de inversión es esencial para entender la lógica bajo la cual se prioriza la inversión en salud. Así, es mucho más fructífera una negociación que tenga como objetivo la construcción de infraestructura o la elección de una ARS que una que busque la contratación de personal médico o de servicios. 
debe quedar por escrito. También se hace inmediatamente un acta en donde firman los involucrados en el acuerdo, más los registros de asistencia. Las reuniones se alargan y la gente se va yendo. Pero se logra llegar a acuerdos (extracto diario de campo, julio de 2001).

En la asociación también se hacen asambleas generales, pero con menor frecuencia que en el resguardo. El transporte restringido, las sequías, eventos sociales -como los funerales- y los costos de manutención de las personas impiden estas reuniones. Cada año se lleva a cabo, al menos, una asamblea, en la que se decide el plan de inversión de los recursos de transferencias y se eligen los representantes legales. Otras reuniones se realizan sólo en los casos de suma importancia y urgencia - proyectos de inversión externa, consulta previa, crisis interna o externa-. La dinámica es la misma descrita antes, con la diferencia de que no la preside el cacique, sino los representantes legales. Durante el transcurso del año, la representante consulta las decisiones con su primo, las autoridades tradicionales y algunos miembros de la comunidad, individual mente.

Una vez acordados los proyectos con las comunidades, los representantes indígenas emprenden procesos de negociación, que implican tiempo, constancia y recursos. Es necesario ir varias veces a los edificios oficiales, hasta ser recibido. Las esperas son largas, furtivos los encuentros en los corredores y breves las citas con los funcionarios. Para llegar a un acuerdo son necesarias las conversaciones prel iminares con mandos medios y con quienes deciden, la utilización de mensajeros o mediadores, el envío de correspondencia -oficios-, etcétera.

En al gunas ocasiones, estos procesos incluyen reuniones en las comunidades, a las que asisten las contrapartes. En el siguiente aparte se describe una reunión entre la ARS y los habitantes del resguardo:

El asesor delacomunidad exponelos problemas principalesdelaatención hospitalaria y del expendio de los medicamentos en la farmacia. Exigen fotocopias de registro de nacimiento o cédula, además del carné. Esto implica gastos y demora en la compra del medicamento. Si no hay fotocopia no seentrega el medicamento, entonces muchos han tenido que comprar la droga con su propia plata. El hospital les exige comprar medicamentos e insumos intrahospital arios, que no son cubiertos por la farmacia porque no pertenecen al POS-S; piden 
hasta las sábanas.

La farmacia no entregará más medicamentos porque no ha firmado contrato y además no le han pagado las facturas [hay diferentes versiones (...) según la ARS el contrato sí está firmado y algunas facturas sí le han sido pagadas].

El hospital se comprometió con varias cosas que no ha cumplido hasta ahora: por ejemplo, separar las fórmulas entre las que secubren con el pos y las que no.

También la ARS se comprometió a apoyar un proceso de fortalecimiento de la medicina tradicional y no ha hecho todavía nada al respecto (extracto diario de campo, julio de 2001).

\section{La que sigue es la intervención de los empleados de la ARS:}

La representante de la entidad toma la palabra e informa sobre las medidas de la ARS: no se exigi rá más la fotocopia de la cédula o del registro civil, sólo el carné. La ARS pagará una "guía", quien estará pendiente de los pacientes que van al hospital y a la farmacia. Ella será la encargada de dar el visto bueno a la fórmula, en su defecto el visto bueno lo dará el asesor, que luego debe ser refrendado por la guía.

Se solicita que se registren los niños antes de los dos meses de nacidos para poder incluirlos en el régimen subsidiado de una manera más eficiente.

Recuenta sus gestiones para lograr que haya un subsidio a la oferta, es decir, que lo que no está cubierto por el POS-S sea cubierto por un fondo que tienen los departamentos para estos casos. La ARS no ha logrado que el departamento de La Guajira responda por estos servicios.

El hospital ha si do subcontratado por la ARS para atender POS-S de Ios indígenas y además para hacer los programas de prevención y promoción. Pero, según la ARS, el hospital no está cumpliendo.

Con respecto a la adecuación de los servicios de salud, es muy difícil. Precisamente, la ARS está muy preocupada por la resolución 412 de $2000^{34}$, porque son exigencias que van en contra de algunas prácticas y concepciones sanitarias indígenas (extracto diario de campo, julio de 2001).

Cuando los representantes in-

34. En la resolución 412 de 2000 "se establecen las actividades, procedimientos e intervenciones de demanda inducida y obligatorio cumplimiento y se adoptan las normas técnicas y guías de atención para el desarrollo de las acciones de protección específica y detección temprana y la atención de enfermedades de interés en salud pública". Aunque menciona las particularidades epidemiológicas de la región cubierta y las modificaciones que por nuevas tecnologías o procedimientos pudieran establecerse, no se refiere a las adaptaciones de dichos procedimientos, actividades dígenas no obtienen resultados e intervenciones a las poblaciones indígenas. 
mediante la estrategia de la negociación, ejercen presión, mediante el uso de la que hemos definido como la segunda estrategia: Ias herramientas jurídicas.

\section{UTILIZACIÓN DE RECURSOS JURÍDICOS}

CUANDO LOS INTERLOCUTORES NO RESPONDEN A LAS DEMANDAS DE LOS gobiernos indígenas, estos apel an a las herrami entas de exigencia ciudadana que definió la constitución: los derechos de petición y las tutelas ${ }^{35}$. Estos recursos jurídicos -que sirven como presión a los otros gobiernos locales o a las instituciones con las que interactúan- son los que generan más confianza en los representantes, además de los contratos o acuerdos escritos y firmados, cuya utilización es constante.

El aseguramiento de los miembros de las comunidades indígenas se basa en censos actualizados. El último censo de la asociación data de 1993 Aunque es competencia de los municipios hacerlos para cumplir con las metas de cobertura, la mayoría aduce la carencia de recursos para no efectuarlos. En algunos casos, los gobiernos indígenas buscan realizarlos ellos mismos para agilizar el proceso de afiliación, como lo hizo el resguardo del sur. Pero para la asociación de la alta Guajira la afiliación al régimen subsidiado se ha convertido en uno de los mayores conflictos con la administración municipal, precisamente por la carencia de datos.

Hasta hace tres años, la representante legal no tenía cifras precisas sobre los afiliados al régi men subsidiado,

Ђٓ El derecho de petición es la solicitud verbal o escrita que se presenta ante un servidor público con el fin de requerir su intervención en un asunto concreto, quien tiene quince días para responder. Es un derecho fundamental, parte de los derechos inherentes a la persona humana. Su petición judicial inmediata puede lograrse mediante el ejercicio de la acción de tutela. La petición irrespetuosa exime a las autoridades de resolver prontamente.

36. ARS indígena original de la Sierra N evada de Santa Marta.
(...), porque de cada asociación se tiene cuatrocientos (...) hasta hace poquito me dijeron que tenían que afiliarnos a la ARS común, yo por ejemplo estoy pidiendo, por medio de derecho de petición, que ya me dijeron que sí, afiliarnos a Dusakawi ${ }^{36}$ (...). Lo que pasa es que arranco aquí, cojo por aquí y no he ido a Uribia a hablar con ese señor que maneja el censo, donde diga Portete, Portete, Portete; yo le tengo 
quellevar ¿un $C D$ en blanco?, un disquete en blanco, para que él me saquemi gentey yo afiliarlos allá, ya medieron la orden, yo sela pedí al a al cal desa y ella me dijo quesí (...) en la asociación de nosotras hay afiliadas como trescientas, pero por todos somos 985 los del censo del 91, no del os que han nacido o han muerto (...) pero fíjate, el año pasado hicieron un censo pero no meacuerdo, no sal ió, para colmo de males a mí metocó en Uribia, mejor dicho eso tienemuchos desórdenes (...) la mayoría del wayuu que salió favorecido, no utiliza ese fondo, esa plata más bien la está absorbiendo la ARS común en donde están los nombres deesas personas (representantelegal dela asociación, 2001).

En 2001, mediante un derecho de petición, la representante solicitó el listado de sus asegurados para transferirlos a otra ARS y se percató de que al gunos aparecían afiliados, a pesar de que no recibieron los carnés y, por tanto, no tuvieron acceso a los servicios médicos. En 2002 ella pidió un nuevo censo para lograr la afiliación de sus miembros a una EPS indígena, a la cual en ese momento ya estaban afiliados veinte. La anterior ARS fue cerrada por incumplimiento de los requisitos y no sabía cuál la reemplazaría. A principios de 2004 no se había hecho aún ningún censo ${ }^{37}$.

Si bien la representante de la asociación insisteen la negociación con la alcal día municipal de Uribia, las acciones que emprende re lacionadas con la salud son independientes de los recursos de transferencia. Ella, como la mayoría de líderes indígenas, está convencida de que el camino para

37. Los costos de un censo son elevados y aunque son una exigencia de las autoridades municipales para asignar nuevas afiliaciones, las comunidades privilegian la financiación de proyectos productivos. Sin embargo, la situación actual es tan caótica que las auto ridades departamentales y municipales anunciaron un censo general de la etnia wayuu para mayo de 2005 mejorar la salud de sus comunidades es "tomándola en sus manos". La formación depersonal médico y la creación de ARs indígenas, aunque todavía en estado incipiente, podrían llegar a ser espacios de gran importancia para el campo de acción delos indígenas en el sistema de salud.

\section{Formación de personal médico y creación de ARS}

D ESDE FINALES DE LA dÉCADA DE 1980, LAS POLítiCAS DE SALUd RELAcionadas con los grupos indígenas han enfatizado sobre la importancia de la formación de personal nativo en el ámbito dela 
salud para garantizar el acceso a y la adecuación cultural delos servicios, así como su eficacia. No hay datos precisos sobre el número de enfermeras, promotores y educadores de sal ud nativos, pero no es despreciable. Sin embargo, después de la reforma, la mayoría de promotores fueron desvinculados del departamento debido a la descentralización de las competencias, transferidas a los municipios ${ }^{38}$.

De modo que en La Guajira el problema en este sentido no es la carencia de personal nativo de atención primaria, sino, más bien, la fal ta de recursos financieros de las entidades territoriales para pagarlo. El resguardo logró un acuerdo con el departamento para mantener una planta de tres promotores de salud, como parte de su PAB. En cambio, Ia asociación cuenta con una sola, quien a pesar de ser wayuu no es aceptada por una de las cuatro comunidades. En efecto, esta promotora puede atender los habitantes de ciertas comunidades de la asociación, pero no de todas, porque sus pobladores se sienten molestos, pues no contrataron a sus propias promotoras. La asociación, por su parte, sólo logró que el municipio contratara una promotora, y las otras quedaron por fuera.

Es cada vez más común que los jóvenes se inscriban en formación en salud, profesiones que les posibilitan la permanencia en las comunidades y un campo laboral; además, las comunidades garantizan así el control sobre sus jóvenes; y, finalmente, ellos se convierten en un puente entre el sistema de sal ud occi-

38. Por ejemplo, a partir de 2002, con el avance del proceso de descentralización, el hospital de Nazareth perdió casi $80 \%$ de su planta de promotores de salud financiada por el departamento, puesto que la competencia se trasladó al municipio.

39. Es preciso anotar que esta es la tendencia actual. Al principio, la formación de jóvenes en el campo sanitario era una manera de integrarlos a la sociedad occidental, darles un lugar por fuera de las comunidades que les permitiera un mejor futuro. En muchas ocasiones, estos no prestaron sus servicios en las comunidades, pues se quedaron en los cascos urbanos e hicieron sus vidas allí. A mediados de la década de $\mathbf{1 9 9 0}$ se observa un cambio en este sentido.

40. Término wayuunaiki utilizado para designar a las personas no indígenas. dental y los usuarios indígenas. Ya que las comunidades respetan su conocimiento, estos agentes de salud nativos son mediadores privilegiados entre ellas y los sistemas desalud ${ }^{39}$.

Sin embargo, los médicos indígenas en La Guajira son pocos. Para la representante, lograr que Ios médicos alijunas ${ }^{40}$ presten sus servicios en la comunidad es una empresa casi imposible. Una de sus frustraciones mayores es que ninguno de los jóvenes de la comunidad en los que tenía de- 


\section{Revista Colombiana \\ de Antropología \\ Volumen 40, enero-diciembre 2004

positada su esperanza estudió medicina.

La formación de personal sanitario indígena es el punto de partida de una tendencia hacia la participación directa de los grupos indígenas en los servicios de sal ud. Los dos gobiernos indígenas consideran la creación de ARS indígenas como la única-o, por lo menos, la mejor- manera de tomar en sus propias manos el desarrollo de la salud de sus comunidades. Según el decreto 30 de 2001, las asociaciones de autori dades tradi cional es o cabildos podrán constituir sus propias ARs indígenas, si disponen de "un patrimonio mínimo equival ente al val or de 150 salarios mínimos legales mensuales vigentes por cada 5000 subsidios administrados" (ley 691de 2001). No obstante, muy pocas veces los resguardos o asociaciones cuentan con dicho patrimonio.

En La Guajira han funcionado por lo menos tres ARs indígenas, pero ninguna ha surgido de un proyecto colectivo o asociativo de las comunidades wayuu; han sido esfuerzos individuales, sin ninguna conexión con los "planes de vida" de Ios resguardos. Actualmente, Ia ARs Dusakawi ofrece sus servicios a los wayuu. Dos problemas básicos ha enfrentado: primero, que su origen indígena no garantiza su dominio del "saber médico indígena", espacio de conocimientos y de prácticas diverso también y que exige adaptaciones locales. Es cierto que estecarácter indígena le confiere una sensibilidad mayor -comparada con las ARS privadas de lógica mercantil- frente a la particularidad de la población que atiende, pero no asegura, necesariamente, su capacidad de satisfacer las exigencias y necesi dades wayuu a partir de los servicios de sal ud que puede contratar en la región.

El segundo problema es general para todas las ARS indígenas: el cumplimiento de las metas general es de salud pública ${ }^{41}$ : por ejemplo, atención institucionalizada de partos, detección temprana de cáncer de cuello uterino y de seno, el tipo de atención de enfermedades de interés en salud pública. La ARS debeentregar a las autoridades competentes informes trimestral es sobreel cumplimiento de estas actividades, difícilmente positivo, dados los

41 como, por ejemplo, la resolución 472 de 2000, ya mencionada, sobre las normas técnicas de obligatorio cumplimiento en relación con las actividades, procedimientos e intervenciones de demanda inducida para el desarrollo de las acciones de protección específica y detección temprana, y las guías de atención para el manejo de las enfermedades de interés en salud pública. Esta resolución establece también los lineamientos para la programación, evaluación y seguimiento de las actividades establecidas en las normas técnicas. 
problemas de articulación con los servicios, las condiciones geográficas de los territorios donde habitan los indígenas, las concepciones y prácticas médicas indígenas, etcétera.

En 2002, los wayuu del sur comenzaron un proceso para constituir una asociación de cabil dos queles permitiera crear su propia ARS O EPS indígena con los beneficios de la venta de Carbocol. Para un asesor indígena, se trataba de un proceso que apenas comenzaba pero que demostraba cierto empoderamiento en las comunidades, que posi bilitaba y abría otros espacios de participación (entrevista, 2002). A mi regreso el año siguiente, los recursos mencionados se habían invertido en tierras para ampliar los resguardos y el proyecto de la ARs había sido pospuesto. En la alta y media Guaji ra comenzó también un proceso de asociación de todas las autoridades tradicional es, que no se completó por múltiples razones, entre las que pueden mencionarse los intereses encontrados de los diferentes representantes, la intervención negativa de al gunos políticos local es y de al gunas autoridades municipal es y, final mente, otras prioridades y urgencias en las que es necesario invertir los presupuestos indígenas.

\section{Los determinantes locales} de las estrategias wayuu y de sus resultados

\footnotetext{
P ARA CUMPLIR CON SUS ROLES, LOS GOBIERNOS INDÍGENAS WAYUU UTIlizan, básicamente, las tres estrategi as descritas en el aparte precedente. Pero sus al cances y la veeduría de los compromisos adquiridos con los interlocutores dependen de los márgenes de maniobra permitidos a los agentes locales. Entendidos como espacios políticos de acción por fuera de la hegemonía del sistema, estos márgenes se ven afectados, a su vez, por las lógicas institucional es y su disposición frente a las dinámicas socioculturales de los wayuu.
}

Entre los momentos más adecuados para emprender negociaciones pueden mencionarse el último mes del año fiscal -antes del 31 de diciembre- y el periodo el ectoral. Las campañas políticas son espacios políticos privilegiados en los que los gobiernos indígenas establecen compromisos de inversión con los candi datos a la gobernación, las al cal días y los concejos. Si el candidato apoyado por la comunidad gana, ésta tiene sus 


\section{Revista Colombiana \\ de Antropología

proyectos garantizados. Pero si no, mientras pasa el mandato de tres años ella sólo contará con sus propios recursos o con otros medios de financiación.

Por ejemplo, un alcal de del municipio del sur fue apoyado por el resguardo durante su campaña electoral, favoreciendo las relaciones entre los gobernantes. En cambio, en Uribia la persona el egi da no fue el candidato apoyado por la asociación, por lo que ésta sólo obtuvo lo mínimo que le compete al municipio.

La distancia del casco urbano y el lugar ocupado por la entidad territorial en el escenario municipal son dos factores objetivos que determinan el margen de maniobra del representante indígena. El hecho de que el municipio del sur sól o tiene en su jurisdicción el resguardo -ubicado a quince minutos- favorece las relaciones entre el cacique y el alcal de, lo que redunda en más recursos, mayor visibilidad y mejor disposición del gobierno municipal para llegar a acuerdos.

En cambio, la representante de la asociación debe hacer frente a un municipio con mayoría poblacional indígena, a la que están inscritas por lo menos dos asociaciones o autoridades tradicionales, lo que dificul ta las relaciones con el gobierno municipal. Trasl adarse a la cabecera munici pal es uno de los mayores obstáculos, puesto que como nunca sabe cuánto durará el trámite que emprende debe estar dispuesta a pagar al ojamiento y comida, además del transporte. Por ello, debe hacer estos trámites sola, dados los gastos que implicaría llevar acompañantes, lo que afecta indirectamente sus relaciones con la comuni dad y su fortaleza en las negociaciones, como se verá más adelante.

El conjunto de atributos de un representante constituye su capacidad para ser creativo y hábil en el uso de sus estrategias, aprovechando al máximo los márgenes de maniobra existentes. Al mismo tiempo, estos atributos individuales amplían o limitan estos espacios de maniobra y en el momento de la relación con las instituciones estatales. En términos generales, es posi ble hablar de las si gui entes características: primero, las que tienen que ver con su origen y posición -la pertenencia familiar y el estatus sociocultural (género, edad, etcétera)- que determinan en gran medida la legitimidad que tenga frente a la comunidad wayuu y su situación en la arena alijuna; segundo, las relacionadas con su recorrido personal -su formación escolar, 
Roles y estrategias de los gobiernos indígenas en el sistema de salud

su competencia lingüística en wayuunaiki y en español, sus alianzas y experiencia en el ámbito político-.

Los líderes que he mencionado compl etaron su educación secundaria y la representante de la alta Guajira cursó, además, estudios técnicos. Tienen competencia lingüística en español, ya que son hijos de padres alijunas y pasaron periodos de su infancia y juventud en los hogares de sus parientes paternos -en Riohacha y Barrancas-. Pero también vivieron durante la primera infancia y en las vacaciones en la ranchería con sus parientes maternos, lo que garantiza su competencia lingüística en wayuunaiki. Tanto sus orígenes familiares maternos como paternos les aseguraron el estatus social quetienen en sus comunidades, pero también les generan, permanentemente, tensiones con otros miembros de las comunidades que gozan del mismo estatus. Su estatus en la sociedad alijuna depende del lugar que puedan lograr a partir de los atributos que he identificado y de otros factores que no puedo desarrollar en este artículo -alianzas con las familias guajiras, lugar en el mundo político-económico guajiro, etcétera-.

La competencia lingüística en ambas lenguas y el nivel de educación inciden en la capacidad de los actores para responder de manera adecuada a las dinámicas del funcionamiento del sistema, específicamente en términos de las interacciones. Un buen manejo del español permite a los representantes situarse mejor frente al administrador o funcionario que tienen como interlocutor: les permite expresar mejor las situaciones y les brinda mayores recursos expositivos y argumentativos.

El hecho de ser mujer, sin embargo, es un factor que juega en contra de la representante legal de la asociación, dado el predominio del machismo en las dinámicas relacionales de La Guajira en el ámbito municipal, dominadas ampliamente por la lógica alijuna. Aunque en la alta y la media la tendencia es a que las mujeres sean líderes y representantes, en la interacción con los actores institucionales -otros gobiernos local es, agencias del estado y entidades privadas- es un factor en contra. No es compl etamente negativo, pues los alijunas están muy familiarizados con el rol público de las mujeres wayuu, pero limita en la medida en que la interacción se define por la dominación masculina-lenguaje, comentarios y bromas, gestos corporalesy por la subval orización de la capacidad femenina para movilizar a su comunidad o para hacer uso de recursos más "agresivos" 


\section{Revista Colombiana \\ de Antropología

en la interacción -volumen de la voz, apelación a advertencias, etcétera-.

Por el contrario, el cacique se inscribe cómodamente en las dinámicas guajiras, pues en el sur la mayoría de líderes políticos son hombres. Gracias a su amplia experiencia política, complementada con una asesoría permanente y el conocimiento de las leyes, tiene una posición ventajosa en el momento de las negociaciones. Pero también él fortalece su posición ante sus interlocutores y evita, en cierta medida, las dudas de las comunidades, al acompañarse siempre de los miembros del cabildo -hombres jóvenes que han terminado, por lo menos, el bachiIlerato-. Al mismo tiempo, Ios forma políticamente y los compromete en las acciones del cabildo.

El cacique está en contacto permanente con su comunidad y la información fluye medianamente bien, lo que implica que ésta si empre esté al tanto de lo que pasa. En este sentido, asume un compromiso mayor con los proyectos de su líder.

En el caso de la asociación, si bien la representante goza de amplia legitimi dad frente a las comunidades de la bahía, el contacto no es permanente y la información fluye parcial y lentamente. A esto se suma que muy pocos miembros dela asociación comprenden la dinámica de los trámites burocráticos, y se impacientan cuando no ven resultados inmediatos. En ciertas ocasiones, la dinámica del clan afecta las relaciones de las comunidades con la representante, puesto que al gunas de sus acciones o trámites pueden ser percibidas como preferenciales a favor de su propio clan, lo que genera malestar en los otros. Hacer los trámites sin acompañantes empeora esta situación, pero los costos económicos no brindan otra posibilidad.

Tanto para el cacique como para la representante, el liderazgo -la representación de sus comunidades- es una labor que exige, por un lado, constancia y fuerza, y, por otro, no siempre produce resultados; además, pone en evidencia las desigual dades de las que forman parte.

Ellos [los gobernantes] no cumplen con lo que prometen; ¿por qué no dicen de una vez que no hay? Sino que mientras, se aprovechan de la persona. Porque si le dicen a uno de una sola vez que no hay, uno no gasta tanto. Esa gastadera deir y venir, deir y venir (...) A mí me da la impresión de que la institución es discriminadora; si el líder es indígena, no es muy atendido; y si es indígena y no tiene un 
nivel de intelectualidad, peor. Porque pobrecito, no lo val oran (...) porque cuando llega:

- ¿Ah, usted lo que necesita es tal cosa?

- Sí, lo que yo quiero es tal cosa.

- Ah, bueno, bueno; sí, sí se le va a hacer.

Y lo sacan ahí mismo. Y ahí lo tienen, yendo y viniendo (...) (representante legal, 2003).

\section{Conclusiones}

A UNQUE EN EL ÁMBITO DE LA REGULACIÓN EL SISTEMA DE SALUD COIombiano proveyó a los indígenas de campos de acción, en su implementación local no tiene la capacidad suficiente para responder de manera adecuada a las necesidades, expectativas y características de estos grupos, y, menos aún, para integrar a su funcionami ento actores no institucionalizados, es decir, los que no se integren bajo sus modelos.

La eficiencia del sistema de sal ud y el logro de sus objetivos -cobertura y calidad- es limitada, por factores ligados a las características propias del mismo, en el que conviven las funciones, competencias y entidades anteriores y actuales. En La Guajira los problemas de funcionamiento se suman a la situación sociodemográfica. Más de $60 \%$ de la población es potencial mente "beneficiaria", lo que implica más esfuerzos y recursos por parte de las entidades territoriales.

A pesar delo anterior, los gobiernos indígenas se involucran cada vez más en el manejo de la salud de sus comunidades y se percatan de la importancia de abogar por la ampliación de la cobertura, el acceso y la calidad de los servicios de salud. No obstante, la pregunta por el margen de maniobra permitido por el sistema a los gobiernos indígenas para desempeñar sus roles revela una característica importante de los sistemas multiculturales. Es decir, que la pregunta pertinente es, ¿cuál es el margen de maniobra que tienen los indígenas para desempeñarse en tanto indígenas dentro del sistema estatal?

La inclusión universal dela "diferencia cultural" tiene como costo la sujeción de la diferencia a los códigos reglamentados por el estado. En efecto, para mantenerse articulados a las instituciones y ser incluidos en el funcionamiento del estado, los 


\section{Revista Colombiana \\ de Antropología

indígenas sól o pueden moverse dentro de los campos de acción y bajo los modelos definidos por el sistema.

Primero, es necesario cumplir con ciertos requi sitos de la indigenidad: título territorial, organización administrativa en la forma de cabildo, autoridad tradicional o asociación de autoridades tradicionales, lengua y "usos y costumbres" distintivos, etcétera. Segundo, para emprender proyectos y obtener el concurso de las instituciones estatal es y los gobiernos regionales y local es es necesario conocer las normas, los conductos adecuados, los trámi tes y los recursos jurídicos.

En este sentido, I os indígenas siguen sus propias estrategias, aprovechando los márgenes de maniobra que permite el sistema. De esta manera, avanzan hacia una situación mejor en el escenario político regional. Pero, al mismo tiempo, la disposición de los actores institucionales frente a los representantes indígenas afecta positiva o negativamente los resul tados de las acciones emprendidas por éstos.

Los roles asignados a los gobiernos indígenas no alcanzan a ser, todavía, verdaderos espacios de acción en los procesos del sistema de salud, sino meras posiciones privilegiadas para presentar demandas. Los gobiernos indígenas preparan "proyectos", "planes", "propuestas" para "presentar" ante los otros gobiernos locales. Las autoridades de los municipios y departamentos son las que, finalmente, "aprueban" los proyectos o las peticiones de Ios indígenas. Más que negociaciones entre pares, estos procesos se revelan como demandas de subordinados frente a las autoridades. A pesar de que la legislación colombiana define las competencias de los gobiernos indígenas sin desmedro de sus necesidades y concepciones de salud y bienestar, en la práctica se trata de un nuevo posicionamiento para hacer demandas al estado y mantener la articulación de lo local.

Una segunda característica de los sistemas multiculturales puede ser identificada entonces: mientras los avances de la articulación indígena con el sistema de salud estatal aún son tímidos, esta misma articulación implica contradicciones dentro de las comunidades. Ligadas a sus dinámicas de reproducción sociocultural, estas contradicciones se expresan en las tensiones en las estructuras de autoridad y de toma de decisión; los conflictos relacionados con la legitimidad de las autoridades o líderes y con el cambio del modelo de acceso al poder; los nuevos 
Roles y estrategias de los gobiernos indígenas en el sistema de salud

model os de representati vi dad acordes con las exigencias estatales; y los conflictos internos causados por las diferencias ideológicas y de intereses políticos y económicos de los miembros de las comunidades.

Actual mente, los gobiernos indígenas son cada vez más conscientes de la importancia del desarrollo de la salud de sus comunidades. Garantizar y mejorar la sal ud son deberes del estado, pero para ello es necesario el esfuerzo de quienes toman las decisiones y los agentes local es para avanzar hacia la adaptación de las instituciones y de los procesos del sistema nacional de salud a las condiciones y poblaciones locales.

\section{Bibliografía}

Alderete, E. (Wara). 1999. The health of indigenous peoples. OMS. Ginebra.

Baum, F. y H. M. Kahssay. 1997. Guidelines for involving health development structures in promoting health or tapping into civil society guidelines for department health systems. WHO Consultancy. Flinders University of South Australia.

Bossert, T. y J. Beauvais. 2002. "Decentralization of health systems in Ghana, Zambia, Uganda and the Philippines: A comparative analysis of decision space" Health Policy and Planning. 17 (1).

Carrillo, J. C. 1996. Plan de salud etnia wayúu. Memorias foro. Cuadernos de Auxología 6. TEA Fundación Auxológica. Bogotá.

Celedón, C. y M. Noé. 2000. "Reformas del sector de la salud y participación social". Revista Panamericana Salud Pública. 8(1/2).

Desalud-Secretaría Departamental de Salud de la Guajira. 2001 Plan de atención básica. Gobernación de La Guajira. Riohacha.

Ekholm-Friedman, Kajsa y Jonathan Friedman. 2005 Essays in global anthropology. Altami ra Press.

Figueras, J., et al. 2002. "Retos para los sistemas sanitarios de Latinoamérica: ¿qué puede aprenderse de la experiencia europea?". Gaceta Sanitaria 16 (1).

Friedman, Jonathan. 2000. "Globalization, class and culture in global systems". Journal of World -Systems research. VI (3).

Gerencia de Asuntos Indígenas de Antioquia. 2000. Aplicación de la legislación indígena en la administración pública. Gobernación de Antioquia. Medellín. 
Gobernación de La Guajira. 2004. Plan de desarrollo departamental 2004-2007. vamos todos a reiniciar La Guajira. Gobernación de La Guajira. Riohacha.

Guevara Garzón, Juan. 1998. "En busca de un modelo de salud para I os puebl os indígena, Ia experiencia del Vaupés" Servicio Seccional de Salud del Vaupés, Ministerio de Salud. Mitú.

Huff, Robert M. y Michael V. KLIR. 1999. Promoting health in multicultural populations. A handbook for practitioners. Sage Publications. Thousand Oaks.

Jaramillo Pérez, Iván. 2001 "Evaluación de la descentralización de la salud en Colombia". Documentos para el desarrollo territorial. 48.

2002. "Evaluación de la descentralización de la salud en Colombia". En Evaluación de la descentralización municipal en Colombia. Balance de una década. Tomo II. Análisis y resultados sectoriales. Departamento Nacional de Planeación UDTDNP. Bogotá.

Londoño, J. L. y FREnK, J. 2000. "Structured pluralism: Towards an innovative model for health system reform in Latin America". En P Lloyd-Sherlock (ed.). Healthcare reform and poverty in Latin America. Institute of Latin American Studies, University of London. Londres.

Ministerio de Salud. 2000. Lineamientos para el desarrollo del plan de atención básica en el año 2000. Ministerio de Salud. Bogotá.

Mooney, Gavin, Stephen Jan y Virginia Wiseman. 2002. "Staking a claim for claims: A case study of resource allocation in Australian Aboriginal Health care". Social Science \& Medicine. 54.

Mosquera, M., ET AL. 2001 "Strengthening user participation through health sector reform in Colombia: A study of institutional change and social representation". Health Policy and Planning. 16 (2).

Movimiento por la Salud Pública-Capítulo de Bogotá. 1998. Memorias grupo de aseguramiento. En http://movsalud.colnodo.org.co/ asegurami ento.htm (08/08/2002).

Nazroo, James y Saffron Karlsen. 2001 Ethnic inequalities in health: Social class, racism and identity. Research findings from the heal th variations program Issue 10 .

Nelson, N. y S. WRIGHT. 1997. "Power and participatory development. Theory and practice". Intermediate Technology Publications. Mimeo.

Organización Mundial de la Salud (OMS). 1999. "International consultation on the health of indigenous peoples". Discourse by Gro Harlem Brundtland, WHO Director-General. OMS. Ginebra. 
Roles y estrategias de los gobiernos indígenas en el sistema de salud

Organización Mundial de la Salud (OMS). 2000. The World health report 2000. Health systems: Improving performance. OMS. Ginebra. Washington.

Iniciativa de salud de los pueblos indígenas OPS/OMS 1995 1998. Plan de acción de la OPS/OMS para el impulso de la iniciativa en la región de las Américas. OPS/OMS. Washington.

1997. Fortalecimiento y desarrollo de los sistemas de salud tradicionales: organización y provisión de servicios de salud en poblaciones multiculturales. OPS/OMS. Washington.

Pinzón, Carlos et al. 1993 Cultura y salud en la construcción de las Américas. Reflexiones sobre el sujeto social. Ican. Bogotá.

Plaza, Beatriz, Ana Beatriz Barona y Norman Hearst. 2001 “Managed competition for the poor or poorly managed competition? Lessons from the Colombian health reform experience". Health Policy and Planning. 16(2).

Puerta Silva, Claudia. 1999. "Aportes desde las concepciones indígenas a los enfoques ecosistémicos sobre el proceso de salud-enfermedad, el bienestar humano y la sal ud ambiental. Estudio de caso: pueblo indígena wayuu". Tesis de pregrado en antropología. Universidad de Antioquia. Medellín.

Rossi, Francisco. 1996. "Iniciativa salud de los pueblos indígenas de América S.A.P.I.A.". En Plan de salud etnia wayúu. Memorias foro. Julio César Carrillo. Cuadernos de Auxología 6. TEA Fundación Auxológica. Bogotá.

Stout, Madeleine y Carlos Coloma. 1993 “Los pueblos indígenas y la salud. Documento base". Seminario-taller OPS-OMS. Winnipeg. Abril.

Vargas, Jorge Enrique. 1997. "Descentralización de los servicios de salud en Colombia". Planeación y desarrollo. 28 (1).

\section{Legislación}

Resolución 10013de 1979.

Ley 14 de 1983

Ley 12 de 1986.

Ley 10 de 1990.

Decreto 1811 de 1990.

Constitución política de Colombia, 1991

Ley 21de 1991 
Resolución 05078 de 1992.

Acuerdo 30 de 1993

Ley 60 de 1993

Decreto 1088 de 1993

Ley 100 de 1993

Decreto 1386 de 1994.

Decreto 1757 de 1994.

Documento Conpes 2773de 1995

Decreto 075/ de 1995

Resoluciones 4288 y 3997 de 1996.

Circular 007 de 1997.

Decretos 77, 78, 79, 89y 91de 1997.

Decreto 1804 de 1999.

Resolución 412 de 2000.

Decreto 30 de 2001

Ley 691 de 2001

Ley 715 de 2001 